\title{
Understanding and Messaging A New Technology for Skin Health: A Mind Genomics Exploration
}

\author{
Konstantin Vuk Savicevic ${ }^{1}$, Klodi Mengri ${ }^{2}$, Attila Gere ${ }^{3}$, Ryan Zemel ${ }^{4}$, Petraq Papajorgji ${ }^{5}$ and Howard Moskowitz ${ }^{6 *}$ \\ 1Tino Space, Cork, Ireland and Belgrade, Serbia \\ ${ }^{2}$ Ti Institute, Tirana, Albania \\ ${ }^{3}$ Szent Istvan University, Budapest, Hungary \\ ${ }^{4}$ Limbic Reviews, Chicago, IL, USA \\ ${ }^{5}$ European University of Tirana, Albania \\ ${ }^{6}$ Mind Genomics Associates White Plains, New York, USA
}

${ }^{\star}$ Correspondence author: Howard Moskowitz, Mind Genomics Associates, Inc., White Plains, NY, USA; Email: mjihrm@sprynet.com

Received: April 06, 2019; Accepted: April 08, 2019; Published: April 20, 2019;

\begin{abstract}
We present the application of the emerging science of Mind Genomics to understand what messages resonate with consumers regarding a skin cosmetic. Experimental design combines sixteen different messages, from four different 'questions' about the product, generating 24 unique vignettes for each of 50 respondents. The deconstruction of the responses reveals what messages best persuade, how messages 'engage' the respondent's attention, how messages synergize or suppress each other when presented together, and then how to extract meaningful mind-sets effectively from a small, affordable, rapid, and easily executable study. Mind Genomics as presented here provides a way to understand the dimensions of everyday life in a scientifically rigorous and meaningful way, generating the potential of a science of behavior from the world previously dominated by one-off commercial efforts.
\end{abstract}

\section{Introduction}

For many years the notion of scientific research to identify the messaging for cosmetics was grudgingly accepted by the 'beautybusiness' for the simple reason that many talented entrepreneurs ruled the business. To these individuals, cosmetics were 'hope in a bottle', a phrased that may have been coined decades ago by Estee Lauder, typifying the attitude that cosmetics, and its sister world, perfumes, were the domain of art and intuition, the substance of magic and wizardry. Perfumery suffered from the 'golden nose' more than did cosmetics. Cosmetics had both aesthetic and functional properties, having to do with our skin. The topics were both beauty and functionality, a dual concern which would lead to the professionalization of the field, and the formation of the Society of Cosmetic Chemists. With the foregoing in mind, we are now three quarters of a century later, in 2019 , as of this writing. The creation of cosmetics is now a science involving a great deal of chemistry as well as innovations in materials science, coupled with the realization and acceptance that the cosmetic product to be sold may be either for beauty or for functionality (skin) or both. Most of the literature in cosmetic science involve the deep study of the product, or better the ingredients of the product, and their combination. The source is biology and toxicology, as well as applied chemistry. There may be some general psychological or sociological studies, but little in the way of specifics relevant to solving a problem. That is, the chemistry of cosmetics, the formulation, and the possible toxicological aspects are part of the science of cosmetics, but the mind of the cosmetic customer is not. Of course there are general studies, but really very few of a specific nature to which a marketer can go to understand that customer mind [1-4] How does one communicate science and beauty in a simple way, especially when the science involves new technology (e.g. fullerenes with nano-properties appropriate for and valuable to cosmetic products; $[5,6]$. What are the words which spark the interest of buyers, perhaps of both sexes? Is there a way to merge science of cosmetics with advertising, more in the manner of an ongoing process than as a fortuitous outcome of years of experimentation with consumers? What might be the happy consequence of a systematic, simple, affordable, scientifically rigorous of knowing how the consumer mind responds to information of both commercial and health importance.

\section{Mind Genomics as the bridge between sales and science}

The analysis of Mind Genomics has evolved from a bespoke, customized approach to one which can be 'templated' both in conception and now in action. The notion of discovering how components of a mixture contribute to the mixture was limited to the harder sciences, biology, chemistry, physics. Most work in applied psychological involved either self-reports or results from surveys. These approaches did not reveal how components drove ideas alone or mixed together to drives together. It would remain a matter of easy computation, and the recognition of creating solutions quickly, inexpensively, and 'scalable' that would led to the Mind Genomics approach. The objective of the analysis is to metricize the ideas in paragraph of ideas (test vignette), or the inverse, to use the metricization of ideas in a paragraph of ideas to understand how each idea operates. 
That is, we use mixtures of ideas, the normal way people see ideas, to understand the performance of single ideas. The approach, when first explained to a non-scientist, non-statistician, appears to fly in the face of the typical canon of science, whose principle rests on the ability to understand something by isolating it, varying it, and then thoroughly understand the idea after it has been put through a microscope.

The foregoing approximation, knowledge of components from measuring systematically varied mixtures, applies perfectly to the topics of Mind Genomics, these topics being the daily situations which confront us, and the decisions that we make in those situations. We cannot easily quantify daily life, although we might ask people to do so, hypothetically, in their mind, separating different ideas. An easier way to do the study and makes the measurements comes from the world of storytelling, and poetry. We can take a set of variables, mix them in different combinations, and instruct respondents to the combinations. The combinations, vignettes really, constitute very short stories. They are easy to rate.

\section{The process of Mind Genomics - from customized science to a templatable operation}

During the past three decades, since 1990, author Moskowitz has developed approaches to understand the mind of consumers using the experimental design of ideas [7] Experimental design involves the systematic combination of variables, and the measurement and analysis of these mixtures to determine how the variables interact to drive the response. Experimental design is not new to product development, whether done informally or formally. Most product developers know that the process of mixing to create different prototypes is the path to developing a better product. The same logic holds when we mix ideas $[8,9]$. The original studies using experimental design of ideas were custom studies without a template. During the past 20 years the effort has moved from custom studies to template studies which generate knowledge more simply and readily [10] The efforts have moved from making the statistics the focus of the research (methodology) to making the application virtually off-the-shelf, so-called DIY (Doit-yourself.)

\section{The process follows these steps:}

1. Define the problem or the topic. This step may seem irrelevant, but it is not. It is quite important to define just WHAT is the focus. For this study, the topic is 'communicating a new cosmetic product, formulated with a novel ingredient (fullerene), responsible for a variety of benefits.

2. Define four questions? The Mind Genomics approach is going to work with combinations of ideas, or elements. The questions allow the researcher to create the sequence of a story through four questions and motivate the answers. The respondents will never see the questions, but they are the key to a successful experiment. The reality continues to emerge that formulating the correct or relevant four questions is the hardest part of the Mind Genomics experiment because it forces the researcher to really think deeply about the topic. (Table 1) presents the four questions (A-D.) In other version of Mind Genomics there may be more or fewer questions.
Table 1. The four questions and the four answers to each question.

\begin{tabular}{|l|l|}
\hline & Question A: My worries about my skin? \\
\hline A1 & Skin is filled with spots \\
\hline A2 & Skin looks old \\
\hline A3 & Skin is dry \\
\hline A4 & Skin bruises \\
\hline & Question B: What does this product do? \\
\hline B1 & Protects with fullerene \\
\hline B2 & Filters out and transforms harmful light \\
\hline B3 & Stimulates lasting production of collagen for three months \\
\hline B4 & Betters skin health, e.g. acne \& wound heeling \\
\hline & Question C: How do I use this product? \\
\hline C1 & Even when your healthy it has beneficial effects \\
\hline C2 & When you're older it makes your skin younger \\
\hline C3 & Use daily as healthy cosmetics \\
\hline C4 & When you're young makes your skin healthy \\
\hline D4 & Question D: What do I observe on my skin? \\
\hline D1 & See the results in 30 days \\
\hline D2 & See what your partner says to you \\
\hline D3 & Look at a mirror, what does it say \\
\hline
\end{tabular}

3. For each question, provide four answers. One of the 'traps' of conventional research is that it relies in many cases on puffery and emotion, but without adequate 'concrete' specifics. That is, the conventional wisdom in much of advertising is to claim benefits, but one does not know the specific benefit, or has not tested the specific benefit. Instead, the common practice is to put in a general benefit. Mind Genomics works at a more concrete level, painting a 'word picture' for each answer. The word picture forces the researcher to think in concrete terms, to describe something to which one can point. In this spirit, the four answers to each of the four questions in Table 1 paint word pictures.

4. Combine the answers (but not the questions) into small vignettes, each vignette comprising a minimum of two answers, and a maximum of four answers. A vignette can incorporate at most one answer from a question, but often the vignette incorporates no answers from a question. (Table 2) shows eight vignettes for respondent \#14, as well as the rating assigned by the respondent, the binary expansion of the rating, and the response time in seconds.

5. Create the vignettes according to the experimental design, run the study, and acquire the data [11] Figure 1 shows an example of one of the vignettes. The respondents are invited to participated by a company (Luc.id, Inc.), a strategic partner of Mind Genomics Associates, Inc. Luc.id maintains access of $20+$ million respondents. For this study the requirements were simply a balance of males 
and females, and approximate balance of ages. The study is run entirely on the Internet, with the respondents being members of the Luc.id panel, ensuring cost effective and rapid completion of the experiment. (Figure 1) shows an example of a vignette.

Plecse read our descriplion for a new skin pruduct that is coming out on June 27, 2019

\section{Consider the ENTIRE VICNETTE as ONE IDEA}

How does this relale to your skin?

\section{Shin is filled with spots}

\section{Filiers out and transforme harmful light}

Use daly as healtty oosmetics
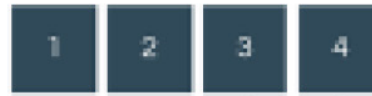

\section{5}
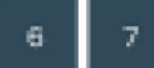

is

\section{g}

Not for me
Figure 1. Example of a vignette as a respondent would see it on a smartphone. The vignette is configured slightly differently for tablets and computers.

6. 'Flag all response times of 9.1 or higher. (Figure 2) shows the distribution of response times for the total panel. All response times of 8.999 seconds or higher were brought to the value 9.0. The distribution suggests an unusually large number of response times beyond 9 seconds. These vignettes were considered to have been evaluated done while the respondents were doing something else. There was no way to check the truth of the assumption, but it seems reasonable in the light of the distribution.

7. Transform the 9-point rating to a binary scale, in preparation for the modeling. The traditional use of scales has been to measure subjective magnitude, as it is done here. Quite often, however, managers have a difficult time understanding the meaning of the scale points. It is far easier to deal with binary responses, no/yes.
The history of consumer research and polling suggests that the data can be more easily accepted by managers and by those having to use the data for technical purposes (e.g., guidance for next steps) when the data are presented in the form of 'no/yes', and the information is presented in terms of percentage saying no versus percentage saying yes. In this spirit we change the response to a binary response, with ratings of 1-6 converted to 0 , and ratings of 7-9 converted to 100 , respectively. We add a small random number $\left(<10^{-5}\right)$ to the ratings to ensure that there is variability in the ratings for a single respondent, even when that respondent assigns all 24 vignettes ratings of 1-6 (converted to 0 ), or ratings of 7-9 (converted to 100.) The stratagem of adding a small random number ensures that the OLS (ordinarily least-squares regression) will always work.

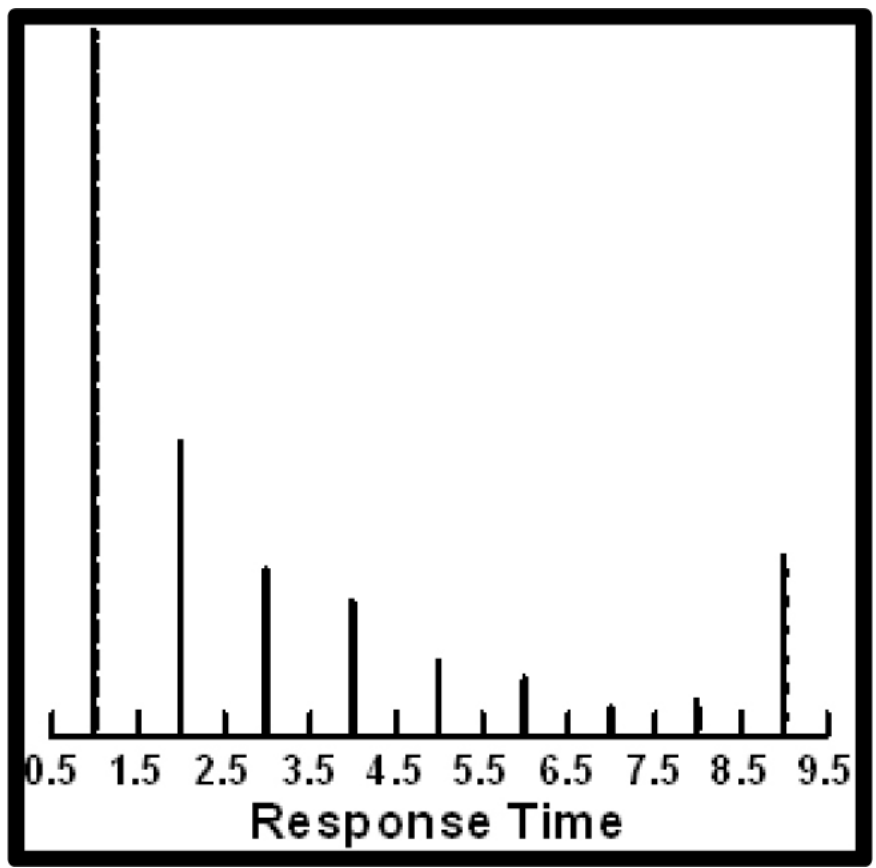

Figure 2. Distribution of response times. Response times over 8.99 seconds were transformed to 9 seconds.

8. Create the data set for modeling. The objective of Mind Genomics is to understand the part-worth contribution of the answers by deconstructing the response to the ratings, after the responses have been converted to binary (ratings of 1-6 converted to 0; rating of 7-9 converted to 100.) We can combine the data from the 50 respondents into large data set, keeping mind that we have extracted the first vignette from each respondent because we assume that to be a learning effort,' and we further extracted all vignettes with response times above 9.02 seconds under the assumption that the respondent was otherwise engaged when reading that particular vignette. We may be eliminating some valid cases, but based upon the distribution of response times, response times of 9 seconds or longer seem to be out of keeping with the rest of the data (see Figure 2).

9. Apply OLS (ordinary least-squares) regression to the data to estimate the part-worth contribution of each of the 16 answers to interest. Previous experience suggests that the responses assigned 
to the first vignette of the 24 may be aberrant, primarily for response time. We eliminate that first vignette from each respondent, as well as eliminating all vignettes flagged as having a response time of 9 seconds or longer. After eliminating the first vignette and the flagged vignettes we are left with 1089 observations or cases, instead of 1200, with 50 observations eliminated as being the first vignette, and 61 observations as registering a suspiciously long response time.

10. We estimate the parameters of the model expressed by the equation: Interest (Binary Transform) $=\mathrm{k}_{0}+\mathrm{k} 1(\mathrm{~A} 1)+\mathrm{k}_{2}(\mathrm{~A} 2) \ldots$ $\left.\mathrm{k}_{16(\mathrm{D}} \mathrm{D}\right)$

Table 2. The data from eight vignettes evaluated by one respondent, showing the combination of answers, the binary expansion, the rating, the binary-transformed rating and the response time.

\begin{tabular}{|c|c|c|c|c|c|c|c|c|}
\hline \multicolumn{9}{|c|}{ Respondent \#14, a woman age 50+, slightly interested in her skin condition } \\
\hline Vignette & 1 & 7 & 9 & 13 & 19 & 20 & 23 & 24 \\
\hline Question A & 3 & 1 & Absent & 1 & 4 & Absent & 4 & 2 \\
\hline Question B & 3 & 2 & 3 & 1 & Absent & 4 & 3 & 3 \\
\hline Question C & 2 & 2 & 3 & 2 & 2 & 1 & 4 & 1 \\
\hline Question D & 3 & Absent & 2 & Absent & Absent & 4 & 3 & 4 \\
\hline \multicolumn{9}{|l|}{ Binary Transformed Design } \\
\hline A1 & 0 & 1 & 0 & 1 & 0 & 0 & 0 & 0 \\
\hline A2 & 0 & 0 & 0 & 0 & 0 & 0 & 0 & 1 \\
\hline $\mathbf{A 3}$ & 1 & 0 & 0 & 0 & 0 & 0 & 0 & 0 \\
\hline A4 & 0 & 0 & 0 & 0 & 1 & 0 & 1 & 0 \\
\hline B1 & 0 & 0 & 0 & 1 & 0 & 0 & 0 & 0 \\
\hline B2 & 0 & 1 & 0 & 0 & 0 & 0 & 0 & 0 \\
\hline B3 & 1 & 0 & 1 & 0 & 0 & 0 & 1 & 1 \\
\hline B4 & 0 & 0 & 0 & 0 & 0 & 1 & 0 & 0 \\
\hline $\mathrm{C} 1$ & 0 & 0 & 0 & 0 & 0 & 1 & 0 & 1 \\
\hline $\mathrm{C} 2$ & 1 & 1 & 0 & 1 & 1 & 0 & 0 & 0 \\
\hline $\mathrm{C} 3$ & 0 & 0 & 1 & 0 & 0 & 0 & 0 & 0 \\
\hline $\mathrm{C4}$ & 0 & 0 & 0 & 0 & 0 & 0 & 1 & 0 \\
\hline D1 & 0 & 0 & 0 & 0 & 0 & 0 & 0 & 0 \\
\hline D2 & 0 & 0 & 1 & 0 & 0 & 0 & 0 & 0 \\
\hline D3 & 1 & 0 & 0 & 0 & 0 & 0 & 1 & 0 \\
\hline D4 & 0 & 0 & 0 & 0 & 0 & 1 & 0 & 1 \\
\hline \multicolumn{9}{|l|}{ Rating } \\
\hline 9-Point Rating & 6 & 7 & 9 & 5 & 7 & 9 & 4 & 6 \\
\hline Binary-Transformed Rating & 0 & 100 & 100 & 0 & 100 & 100 & 0 & 0 \\
\hline Response Time (Seconds) & 9.01 & 5 & 7 & 4 & 3 & 4 & 4 & 4 \\
\hline
\end{tabular}

\section{Results - Total Panel - Interest}

(Table 3) shows the coefficients, $\mathrm{t}$-statistic and $\mathrm{p}$-value for the key parameters of the model relating the presence/absence of the 16 elements to the binary-transformed rating. The model is created on the basis of the 1089 cases, namely without those vignettes in the first position, and without those vignettes with response times of 9 seconds or longer. The additive constant tells us the expected percent of respondents who say that they would be interested in the cosmetic product, but without knowing anything more about the product. The additive constant is a purely estimated parameter, since all vignettes by design comprised $2-4$ elements. The additive constant, 36.45 , tells us that only about $1 / 3$ of the responses will be strongly positive. It will have to be the elements which do the work. The t-statistic is a measure of signal to noise, with values of 1.65 or being what we would call 'significant,' i.e., we can be pretty sure that the additive constant 
(or other parameter) does not come from a distribution which has a real value of 0 . The important thing to note here is not the $\mathrm{t}$-statistic or the p-value, but rather the magnitude of the coefficient. A rule of thumb is that a coefficient is 'relevant' when it is about 7-8 or higher. Based upon that rule of thumb, the only element which really can be considered 'relevant' is C3; Use daily as healthy cosmetics. For whatever reason, the other elements are simply unable to generate interest when they are presented in these vignettes, whereas C3 generates interest.

Table 3. Performance of the elements for the total panel, without the first vignette, and without any vignettes showing a response time of 9 seconds or longer.

\begin{tabular}{|c|c|c|c|c|}
\hline & & Coefficient & t-statistic & p-Value \\
\hline & Additive constant & 36.45 & 4.64 & 0.00 \\
\hline $\mathrm{C} 3$ & Use daily as healthy cosmetics & 7.36 & 1.53 & 0.13 \\
\hline $\mathrm{C} 2$ & $\begin{array}{l}\text { When you're older it makes your } \\
\text { skin younger }\end{array}$ & 4.96 & 1.04 & 0.30 \\
\hline $\mathrm{C} 1$ & $\begin{array}{l}\text { Even when your healthy it has } \\
\text { beneficial effects }\end{array}$ & 3.54 & 0.74 & 0.46 \\
\hline $\mathrm{C} 4$ & $\begin{array}{l}\text { When you're young makes your } \\
\text { skin healthy }\end{array}$ & 3.39 & 0.71 & 0.48 \\
\hline D1 & See the results in 30 days & 1.95 & 0.41 & 0.68 \\
\hline B1 & Protects with fullerene & -0.18 & -0.04 & 0.97 \\
\hline D3 & $\begin{array}{l}\text { Look at a mirror, what does } \\
\text { it say }\end{array}$ & -1.76 & -0.37 & 0.71 \\
\hline A3 & Skin is dry & -1.83 & -0.38 & 0.70 \\
\hline B3 & $\begin{array}{l}\text { Stimulates lasting production of } \\
\text { collagen for three months }\end{array}$ & -1.97 & -0.40 & 0.69 \\
\hline A2 & Skin looks old & -2.58 & -0.54 & 0.59 \\
\hline B4 & $\begin{array}{l}\text { Betters skin health, e.g. acne \& } \\
\text { wound heeling }\end{array}$ & -2.68 & -0.55 & 0.58 \\
\hline B2 & $\begin{array}{l}\text { Filters out and transforms } \\
\text { harmful light }\end{array}$ & -2.91 & -0.60 & 0.55 \\
\hline A1 & Skin is filled with spots & -3.75 & -0.78 & 0.44 \\
\hline D2 & $\begin{array}{l}\text { See what your partner says to } \\
\text { you }\end{array}$ & -4.25 & -0.90 & 0.37 \\
\hline D4 & $\begin{array}{l}\text { Share with your friends so they } \\
\text { all as good as you }\end{array}$ & -5.12 & -1.07 & 0.29 \\
\hline A4 & Skin bruises & -5.49 & -1.13 & 0.26 \\
\hline
\end{tabular}

\section{Performance of elements - Key subgroups - WHO THE RESPONDENTS ARE}

We expect that respondents of different genders and different ages will differ in the pattern of what they find interesting, especially in a skin product. Does that different manifest itself for this new product? The easiest way to answer that question is to do the modeling separately for each key group, beginning with gender (two parallel analyses), and then by age (three parallel analyses.) (Table 4 ) shows the results.

In terms of gender, women are more interested in the topic than are men. This difference in interest emerges from the additive constant, which is 43 for females, and 30 for males, respectively.
Table 4. Performance of the elements for the total panel, the two genders, and three age groups, estimated without the first vignette, and without any vignettes showing a response time of 9 seconds or longer.

\begin{tabular}{|c|c|c|c|c|c|c|c|}
\hline & & $\overrightarrow{\underline{\partial}}$ & $\frac{3}{2}$ & 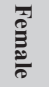 & 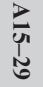 & $\begin{array}{l}\vec{\omega} \\
\stackrel{0}{0} \\
\text { to }\end{array}$ & $\begin{array}{l}\vec{u} \\
\text { ù }\end{array}$ \\
\hline & CONSTANT & 36 & 30 & 43 & 32 & 18 & 74 \\
\hline $\mathrm{C} 3$ & Use daily as healthy cosmetics & 7 & 11 & 3 & 13 & 12 & -1 \\
\hline $\mathrm{C} 2$ & $\begin{array}{l}\text { When you're older it makes your } \\
\text { skin younger }\end{array}$ & 5 & 4 & 6 & 3 & 10 & 9 \\
\hline $\mathrm{C} 1$ & $\begin{array}{l}\text { Even when your healthy it has } \\
\text { beneficial effects }\end{array}$ & 4 & 4 & 3 & 8 & 7 & -2 \\
\hline $\mathrm{C} 4$ & $\begin{array}{l}\text { When you're young makes your } \\
\text { skin healthy }\end{array}$ & 3 & 7 & 0 & 6 & 11 & -2 \\
\hline D1 & See the results in 30 days & 2 & 4 & -1 & -4 & 3 & 3 \\
\hline B1 & Protects with fullerene & 0 & 1 & -1 & 2 & -3 & -3 \\
\hline A3 & Skin is dry & -2 & -3 & -1 & -7 & 11 & -11 \\
\hline B3 & $\begin{array}{l}\text { Stimulates lasting production of } \\
\text { collagen for three months }\end{array}$ & -2 & -8 & 5 & -6 & 9 & -13 \\
\hline D3 & Look at a mirror, what does it say & -2 & 1 & -4 & 1 & -6 & 4 \\
\hline A2 & Skin looks old & -3 & -5 & -1 & -6 & 3 & -6 \\
\hline B2 & $\begin{array}{l}\text { Filters out and transforms harmful } \\
\text { light }\end{array}$ & -3 & -4 & -1 & -5 & -2 & -2 \\
\hline B4 & $\begin{array}{l}\text { Betters skin health, e.g. acne \& } \\
\text { wound heeling }\end{array}$ & -3 & 2 & -7 & -2 & -2 & -2 \\
\hline A1 & Skin is filled with spots & -4 & -8 & 0 & -4 & -1 & -6 \\
\hline D2 & See what your partner says to you & -4 & -3 & -6 & -2 & -9 & 2 \\
\hline A4 & Skin bruises & -5 & 0 & -12 & -4 & -1 & -13 \\
\hline D4 & $\begin{array}{l}\text { Share with your friends so they all } \\
\text { as good as you }\end{array}$ & -5 & -1 & -9 & -4 & -7 & -7 \\
\hline
\end{tabular}

In terms of strong performing elements, however, we have only one strong performer for either gender, C3, Use daily as healthy cosmetics.

We see greater differences among groups when we divide respondents by age. The additive constant for the oldest respondents, age $50+$, is a remarkable 74 . They begin interested, but some elements reduce their interest.

The middle group in terms of age are those respondents ages $39-49$, with the lowest additive constant, but with the most impactful elements.

The youngest age group, 15-29, are interested, especially when the emphasis is on health $(\mathrm{C} 3, \mathrm{C} 1)$.

We see no response to specific ingredients, e.g. fullerene.

\section{Performance of elements - Key subgroups - HOW THE RESPONDENTS THINK}

The division of respondents into self-defined skin concern (none/ low versus moderate/high) shows a higher additive for those who 
define themselves as moderately to very concerned about their skin, and a lower additive constant for those who define themselves as not concerned or only slightly concerned with their skin (46 vs 31.) No elements, however, break through as driving interest. When we move to mind-sets, obtained by the method of clustering patterns of coefficients, we find that two mind-sets emerge. The clustering method puts the 50 respondents into two groups, based upon how 'distance' the respondents are from each other, in a mathematical sense. Distance between two people is based upon the simple number (1-Pearson Correlation.) The Pearson Correlation, R, measures the strength of a linear relation between two groups of data, with comparable measures. Our respondents generate 16 coefficients. When two respondents generate coefficients perfectly linearly related to each other $(\mathrm{R}=1)$, we assume that their distance is 0 , namely $1-1$ $=0$. When two respondents generate coefficients perfect inversely related to each other $(\mathrm{R}=-1)$, we assume their distance to be 2 , namely $1--1=2$. The clustering program (K-Means) assigns respondents to two and then three complementary groups, clusters, based upon mathematical considerations only, namely the distance between the respondents within a cluster is small, and the distance between the centroids of the clusters is large. Based upon this analysis, we find that two clusters suffice, as shown in (Table 5) (last two data columns.) We have sorted Table 5 by the strongest elements in the two mind-sets. Both mind-sets have virtually identical additive constants (38 vs 37 .) The mind-sets will differ in the nature of the elements which score highest. From those elements we will name the mind-sets.

$$
\text { Mind-Set } 1=\text { Speed of action }
$$

Mind-Set $2=$ Skin health

\section{Finding the respondents in the population}

Respondents can be easily classified according to WHO they are, but not easily classified into the WAY THEY THINK, especially when the way they think pertains to specifics, of a particular situation such as a new product. Researchers have classified respondents into very large groups, psychographic mind-sets differing along many general aspects of a topic, such as those who are eco-conscious versus those who are not. These large-scale psychographic studies are expensive to run, require many respondents, take a long time to analyze, and work only for 'general' topics. The opportunity in this study focuses on specific mind-set segmentation, for a limited topic, relatively small scale. For most of one's life, especially experiences of the every-day, the mind-set segmentation is small-scale, specific, and does not warrant the large expenditures. In view of this need to increase the speed and decrease the cost to deploy the results, we have developed a simple system, the PVI or personal viewpoint identifier.

1. The strategy for the PVI follows these steps for a two-segment (cluster) solution in terms of mind-sets:

2. Begin with the 2 vectors containing the 16 coefficients of the elements.

3. Subtract the two vectors (element by element) and compute their absolute value (e.g. abs(x-y))
4. Look for the five highest values e.g. look for the elements which are the farthest from each other.

5. Open a new worksheet in excel and list the five elements under each other.

6. Each chosen element receives one vote (all the chosen ones from step 2).

7. Begin again with Step 1, but now add a standard random noise to our two vectors (random numbers around the mean of the original values) - this step is called Monte Carlo simulation

8. Repeat 2,3 and 5 on the new data just created and sum up the votes

9. Repeat steps 5 and 61000 times - this is called bootstrapping8) at the and we look at the table created in step 4 and chose those 5 elements which were chosen as most discriminating the most times.

Table 5. Performance of the elements for the total panel, self-rated concern with skin, and mind-sets, estimated without the first vignette, and without any vignettes showing a response time of 9 seconds or longer.

\begin{tabular}{|c|c|c|c|c|c|c|}
\hline & & $\overrightarrow{\frac{\partial}{\ddot{E}}}$ & 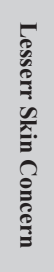 & 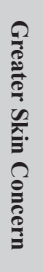 & 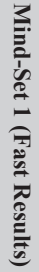 & 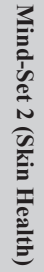 \\
\hline & CONSTANT & 36 & 31 & 46 & 38 & 37 \\
\hline $\mathrm{C} 1$ & $\begin{array}{l}\text { Even when your healthy it has beneficial } \\
\text { effects }\end{array}$ & 4 & 3 & 6 & -6 & 12 \\
\hline $\mathrm{C} 3$ & Use daily as healthy cosmetics & 7 & 6 & 9 & 2 & 11 \\
\hline $\mathrm{C} 2$ & $\begin{array}{l}\text { When you're older it makes your skin } \\
\text { younger }\end{array}$ & 5 & 7 & 3 & 0 & 8 \\
\hline $\mathrm{C} 4$ & $\begin{array}{l}\text { When you're young makes your skin } \\
\text { healthy }\end{array}$ & 3 & 5 & 1 & -2 & 8 \\
\hline D1 & See the results in 30 days & 2 & 3 & 0 & 8 & -5 \\
\hline D3 & Look at a mirror, what does it say & -2 & -4 & 1 & 4 & -8 \\
\hline B1 & Protects with fullerene & 0 & -3 & 5 & 2 & -2 \\
\hline B4 & $\begin{array}{l}\text { Betters skin health, e.g. acne \& wound } \\
\text { heeling }\end{array}$ & -3 & -6 & 2 & 2 & -8 \\
\hline D4 & $\begin{array}{l}\text { Share with your friends so they all as } \\
\text { good as you }\end{array}$ & -5 & -10 & 0 & -1 & -10 \\
\hline B2 & Filters out and transforms harmful light & -3 & -1 & -5 & -2 & -5 \\
\hline $\mathrm{D} 2$ & See what your partner says to you & -4 & -3 & -7 & -3 & -6 \\
\hline A1 & Skin is filled with spots & -4 & -5 & -2 & -4 & -4 \\
\hline A3 & Skin is dry & -2 & -2 & -1 & -6 & 1 \\
\hline B3 & $\begin{array}{l}\text { Stimulates lasting production of collagen } \\
\text { for three months }\end{array}$ & -2 & 0 & -5 & -6 & 1 \\
\hline A4 & Skin bruises & -5 & -5 & -6 & -7 & -3 \\
\hline A2 & Skin looks old & -3 & -5 & 1 & -8 & 2 \\
\hline
\end{tabular}


In the case of 3 segments we do the same but in the first step we create 3 additional variables (S1-S2, S1-S3 and S2-S3) instead of one variable (S1-S2) and choose 6 elements not five. The actual implementation of the PVI for this cosmetic study appears in (Figure 3), showing the questionnaire, and the two feedback screens, each screen for the mind-set to which the new respondent is assigned. The questionnaire and the screen can be used in person in stores, on the web for e-commerce to direct the shopper to the more appropriate website for the shopper's newly uncovered mind-set, and of course for research into covariates with mind-sets. As of this writing (April, 2019) the PVI for the cosmetic product study can be found at this location http://162.243.165.37:3838/TT22/

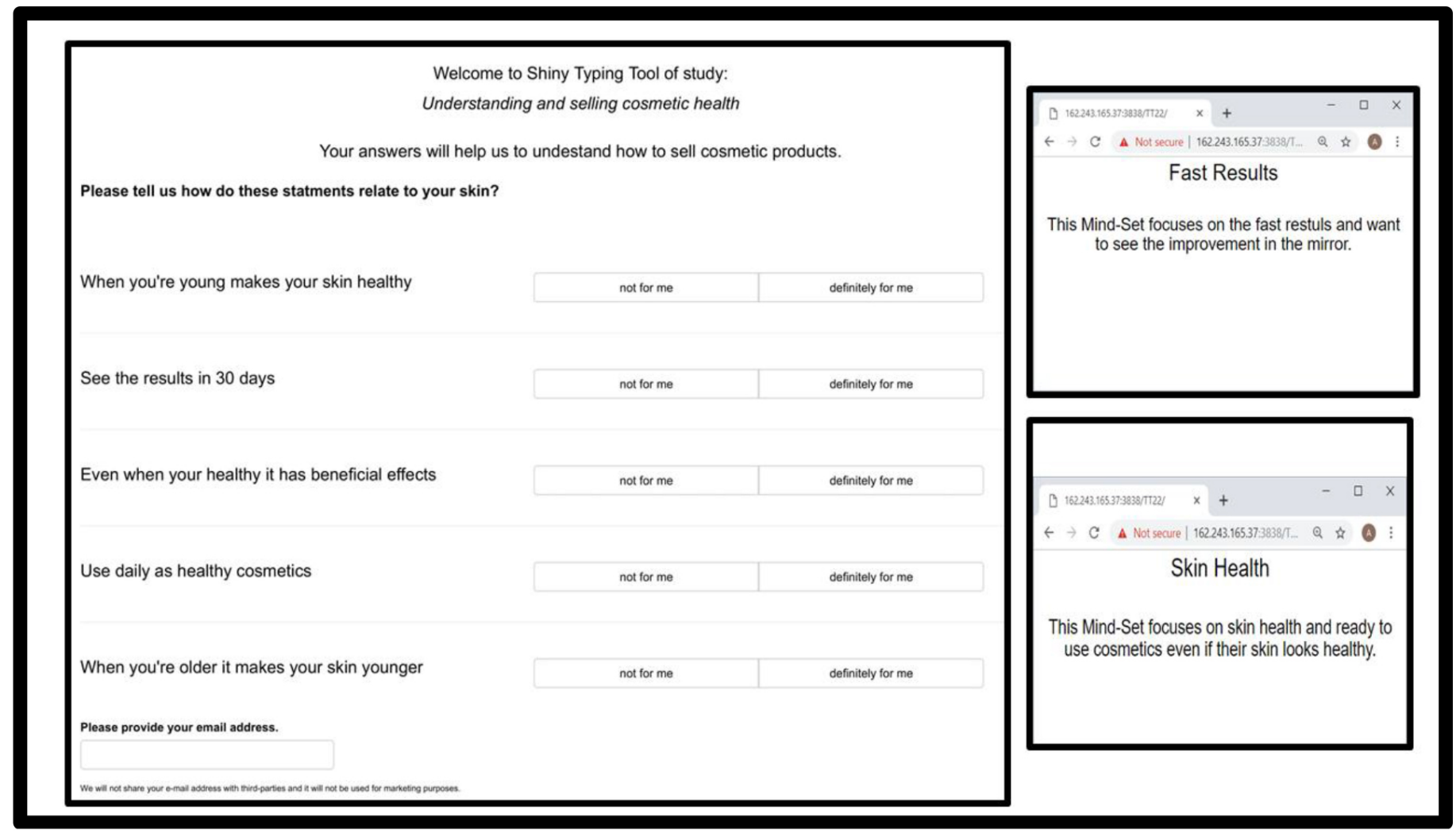

Figure 3. The PVI for the cosmetic product.

\section{Discovering which messages engage, capturing attention}

Today's world has often been characterized as one with the scarcest commodity being the attention of people, who are bombarded daily with a myriad of messages, and who, all too often, 'tune out.' Can the experimental design so useful to discover what 'influences,' also be used to discover what' engages?' One way to answer this question measures the response time for each vignette, and then deconstructs the response time into the component response times of the elements. Those elements with long response times (e.g., 1.0 seconds or longer, an operational definition for convenience in this study) may be assumed to be those which capture attention.

Parenthetical note: Increasing experience with the deconstruction of response time in these Mind Genomics studies suggests that studies with commercial products and 'fun' experiences generate short response times for the different elements, often response times ranging from 0.3 seconds to 0.7 seconds. In contrast, studies of more serious topics, of psychological or sociological relevance, conducted with the same type of respondent population reveal long response times of 1.0 or longer the various elements.
(Tables 6A and 6B) show the response times for the 16 elements, in decreasing order. Table $6 \mathrm{~A}$ shows the response times for the genders and three age groups. Table $6 \mathrm{~B}$ shows the response times for what people feel about their skin and their mind-sets, based upon their interest ratings. The key differences in response time emerge in Table $6 \mathrm{~A}$, showing $\mathrm{WHO}$ the person is, and NOT in Table $6 \mathrm{~B}$, showing how the person THINKS.

Total - No engaging elements

Males - No engaging elements, shorter response times than those for females

Females - Most engaging elements come from Question B, 'what does the product do?'

Age 15-29 - Nothing engages

Age 30-49 - Health and protection, but skip over feedback as if it were consciously ignored

Age 50+ - Health and protection, with feedback from others, i.e., have accepted the situation

No/Low skin concern - engaged by the term fullerene

Med/High concern - nothing engages them

Mind-Sets 1 and 2 - nothing engages them 
Howard Moskowitz (2019) Understanding and Messaging A New Technology for Skin Health: A Mind Genomics Exploration

Table 6A. Response times for key subgroups, based upon WHO THE RESPONDENT IS.

\begin{tabular}{|c|c|c|c|c|c|c|c|}
\hline & & Total & Male & Female & A15-29 & A30-49 & A50+ \\
\hline B1 & Protects with fullerene & 0.9 & 0.7 & 1.1 & 0.6 & 1.1 & 1.3 \\
\hline B2 & Filters out and transforms harmful light & 0.9 & 0.8 & 1.0 & 0.4 & 1.0 & 1.5 \\
\hline B4 & Betters skin health, e.g. acne \& wound heeling & 0.9 & 0.7 & 1.1 & 0.5 & 1.3 & 1.1 \\
\hline A4 & Skin bruises & 0.7 & 0.7 & 0.7 & 0.5 & 0.5 & 1.1 \\
\hline B3 & Stimulates lasting production of collagen for three months & 0.7 & 0.6 & 0.8 & 0.6 & 0.9 & 0.7 \\
\hline $\mathrm{C} 2$ & When you're older it makes your skin younger & 0.7 & 0.7 & 0.7 & 0.2 & 1.1 & 1.0 \\
\hline A1 & Skin is filled with spots & 0.6 & 0.6 & 0.5 & 0.5 & 0.5 & 0.8 \\
\hline $\mathrm{A} 2$ & Skin looks old & 0.6 & 0.6 & 0.6 & 0.2 & 0.6 & 1.1 \\
\hline $\mathrm{C} 3$ & Use daily as healthy cosmetics & 0.6 & 0.6 & 0.5 & 0.3 & 1.1 & 0.4 \\
\hline D4 & Share with your friends so they all as good as you & 0.6 & 0.3 & 0.8 & 0.6 & 0.3 & 1.0 \\
\hline $\mathrm{A} 3$ & Skin is dry & 0.5 & 0.4 & 0.5 & 0.3 & 0.4 & 0.7 \\
\hline $\mathrm{C} 4$ & When you're young makes your skin healthy & 0.5 & 0.5 & 0.5 & 0.2 & 1.1 & 0.0 \\
\hline D2 & See what your partner says to you & 0.5 & 0.4 & 0.6 & 0.8 & 0.1 & 1.0 \\
\hline D3 & Look at a mirror, what does it say & 0.5 & 0.2 & 0.7 & 0.5 & 0.1 & 1.2 \\
\hline $\mathrm{C} 1$ & Even when your healthy it has beneficial effects & 0.4 & 0.3 & 0.6 & 0.1 & 0.9 & 0.2 \\
\hline D1 & See the results in 30 days & 0.3 & 0.0 & 0.7 & 0.3 & 0.2 & 0.7 \\
\hline
\end{tabular}

Table 6B. Response times for key subgroups, based upon WHAT THE RESPONDENT THINKS.

\begin{tabular}{|c|c|c|c|c|c|c|}
\hline & & Total & $\begin{array}{l}\text { None/Low } \\
\text { Concern }\end{array}$ & $\begin{array}{l}\text { Medium / High } \\
\text { Concern }\end{array}$ & $\begin{array}{l}\text { Mind-Set } 1 \text { - } \\
\text { Fast Results }\end{array}$ & $\begin{array}{l}\text { Mind-Set } 2 \text { - } \\
\text { Skin Health }\end{array}$ \\
\hline B1 & Protects with fullerene & 0.9 & 1.1 & 0.7 & 0.9 & 0.9 \\
\hline $\mathrm{B} 2$ & Filters out and transforms harmful light & 0.9 & 0.9 & 0.8 & 0.9 & 0.8 \\
\hline B4 & Betters skin health, e.g. acne \& wound heeling & 0.9 & 0.9 & 0.8 & 0.8 & 1.0 \\
\hline A4 & Skin bruises & 0.7 & 0.6 & 0.8 & 0.6 & 0.8 \\
\hline B3 & $\begin{array}{l}\text { Stimulates lasting production of collagen for three } \\
\text { months }\end{array}$ & 0.7 & 0.8 & 0.5 & 0.7 & 0.7 \\
\hline $\mathrm{C} 2$ & When you're older it makes your skin younger & 0.7 & 0.8 & 0.5 & 0.6 & 0.8 \\
\hline $\mathrm{A} 1$ & Skin is filled with spots & 0.6 & 0.6 & 0.4 & 0.5 & 0.6 \\
\hline $\mathrm{A} 2$ & Skin looks old & 0.6 & 0.6 & 0.5 & 0.5 & 0.6 \\
\hline $\mathrm{C} 3$ & Use daily as healthy cosmetics & 0.6 & 0.6 & 0.5 & 0.5 & 0.7 \\
\hline D4 & Share with your friends so they all as good as you & 0.6 & 0.6 & 0.5 & 0.7 & 0.4 \\
\hline $\mathrm{A} 3$ & Skin is dry & 0.5 & 0.5 & 0.4 & 0.4 & 0.5 \\
\hline $\mathrm{C} 4$ & When you're young makes your skin healthy & 0.5 & 0.6 & 0.4 & 0.5 & 0.6 \\
\hline D2 & See what your partner says to you & 0.5 & 0.5 & 0.5 & 0.7 & 0.3 \\
\hline D3 & Look at a mirror, what does it say & 0.5 & 0.6 & 0.3 & 0.6 & 0.3 \\
\hline $\mathrm{C} 1$ & Even when your healthy it has beneficial effects & 0.4 & 0.5 & 0.2 & 0.2 & 0.6 \\
\hline D1 & See the results in 30 days & 0.3 & 0.4 & 0.4 & 0.6 & 0.1 \\
\hline
\end{tabular}




\section{Scenario Analysis - Deeper 'mental processing' revealed by the pairwise interaction of elements}

One of the premises of Mind Genomics is that the deconstruction of the vignettes into elements can reveal the way the mind processes information. Up to now, we have operated under the assumption that the elements we selected, our 16 answers to the questions, are statistically independent of each other. We ensured that statistical independence by permutable experimental designs [11] The structure of the permutations ensures that each respondent evaluated combinations in which the elements were statistical independent of each other. What happens, however, if the mind somehow deals with the combinations in a way which takes into account the logical coherence or lack of coherence of the elements? Said differently, when we look at vignettes with one type of stated condition (e.g., A1: skin is filled with spots) versus vignettes with another type of stated condition, A3: skin is dry), do we see any effect on the performance of the other elements (B1-B4, C1-C4, D1-D4, respectively)? This question, the nature of pairwise interactions between elements, can never be answered in conventional work with experimental design or conjoint measurement, simply because the combinations can never be tested both for single elements and for combinations of elements.

One way to look at these interactions separated the se of 1240 vignettes from the total panel into five strata, depending upon the element from Question A (skin condition) appearing in the vignette. The structure of the design allows us to separate these strata, then to create a model relating the presence/absence of the other 12 elements to interest and response time. Rather than one model, we end up with five parallel models. Question A or Silo A, skin condition, does not appear. When we look at the different scenarios, we see dramatic differences both in the additive constant and in the values of the coefficients. (Table 7) shows the coefficients for the scenario analysis, with the key stratification variable being Question or Silo A, skin condition.

Table 7. Scenario analysis, showing how each specific statement about Skin Condition (Question 1) interacts with the remaining elements, based upon the rating of the vignette.

\begin{tabular}{|c|c|c|c|c|c|c|}
\hline & & $\begin{array}{l}\text { A0 No condi- } \\
\text { tion }\end{array}$ & $\begin{array}{l}\text { A1 Skin is filled } \\
\text { with spots }\end{array}$ & $\begin{array}{l}\text { A2 Skin } \\
\text { looks old }\end{array}$ & $\begin{array}{l}\text { A3 Skin } \\
\text { is dry }\end{array}$ & $\begin{array}{l}\text { A4 Skin } \\
\text { bruises }\end{array}$ \\
\hline & Additive constant & 22 & 44 & 28 & 23 & 40 \\
\hline B4 & Betters skin health, e.g. acne \& wound heeling & 17 & -16 & -3 & 7 & -15 \\
\hline $\mathrm{C} 4$ & When you're young makes your skin healthy & 11 & 2 & 1 & 2 & 2 \\
\hline $\mathrm{B} 1$ & Protects with fullerene & 8 & -4 & 2 & -3 & 1 \\
\hline $\mathrm{B} 2$ & Filters out and transforms harmful light & 8 & -14 & 7 & 0 & -6 \\
\hline $\mathrm{C} 3$ & Use daily as healthy cosmetics & 5 & 18 & -7 & 5 & 15 \\
\hline D2 & See what your partner says to you & -7 & -8 & 9 & 8 & -16 \\
\hline D1 & See the results in 30 days & 5 & -4 & 8 & 17 & -15 \\
\hline $\mathrm{C} 2$ & When you're older it makes your skin younger & 4 & 4 & -4 & 13 & 7 \\
\hline $\mathrm{C} 1$ & Even when your healthy it has beneficial effects & 6 & 3 & 3 & -1 & 7 \\
\hline B3 & Stimulates lasting production of collagen for three months & 7 & -16 & 4 & 2 & 0 \\
\hline D3 & Look at a mirror, what does it say & -2 & 1 & 4 & 3 & -9 \\
\hline D4 & Share with your friends so they all as good as you & 4 & -21 & 4 & 5 & -15 \\
\hline
\end{tabular}

The additive is the estimated value of the vignette when only the column element appears (e.g., A1, Skin is filled with spots), but no other elements appear. Thus, when we have absolutely no elements, the additive constant is 22 because the value is 22 for A0. When we go from absolutely no elements to different skin conditions, we find two very strong elements, A2 (skin is filled with spots) and A4 (skin bruises). The additive constants are very moderate ( 44 for spots, 40 for bruises). When we move from repair to appearance, we drop down to 28 (skin looks old) and 23 (skin is dry), respectively. Thus, we learn a great deal about the deep structure of decision making. We now move to interactions, after having factored out basic interest and specific issues, the basic interest from the additive constant A0 (22) and the specific issues provided by the additive constants for A0 - A4. Depending upon the particular issues with the skin, the same element may perform strongly or weakly. An example of this dependence of one element on another is the performance of two elements: D2 (See what your partner says to you) and D1 (See the results in 30 days). Both perform well in the present of $\mathrm{A} 1$ (skin looks old) and $\mathrm{A} 3$ (skin is dry) but poorly in the presence of A1 (skin is filled with spots) and A4 (skin bruises).

The benefit of the permuted designs for Mind Genomics become more apparent when we realize that the scenario analysis to discover hitherto unexpected interactions, positive synergisms and negative suppressions, could not have been possible with the permutations. 
The conventional research using conjoint analysis and one set of test stimuli could never have explored the proper combinations, and even were these combinations to have been tested, one would not have the design nor the analytical tools to uncover them.

\section{Scenario Analysis - Deeper 'understanding of engagement' revealed by interaction of elements}

We conclude the analysis with a parallel question about pairwise interactions, this time looking at response times. Whereas the ratings assigned to the vignettes were conscious, or at least the respondent was cognitive aware, the response times represent more automatic responses. We might expect that the response times for the same element would be unchanged in the presence of different messages about skin condition. That is, we expected it should take the same time to respond to an element, no matter what other elements are present with the element in question.

(Table 8) shows dramatic differences in response time to the same element as a function of the basic skin condition in the vignette. A good example of the interactions is three elements: Protects with fullerene; Filters out and transforms harmful light; and Stimulates lasting production of collagen for three months. These three elements are glossed over when the vignette is about dry skin. Yet, when the skin looks old, they engage the respondent, who pays attention.

Table 8. Scenario analysis, showing how each specific statement about Skin Condition (Question 1) interacts with the remaining elements, based upon the response time to the vignette.

\begin{tabular}{|c|c|c|c|c|c|c|}
\hline & & A0: No Condition & $\begin{array}{l}\text { A1: Skin is filled } \\
\text { with spots }\end{array}$ & $\begin{array}{l}\text { A2: Skin } \\
\text { looks old }\end{array}$ & $\begin{array}{l}\text { A3: Skin is } \\
\text { dry }\end{array}$ & $\begin{array}{c}\text { A4: Skin } \\
\text { bruises }\end{array}$ \\
\hline B1 & Protects with fullerene & 1.9 & 1.5 & 1.2 & 0.6 & 0.6 \\
\hline B2 & Filters out and transforms harmful light & 1.9 & 0.5 & 1.3 & 0.9 & 0.8 \\
\hline B3 & Stimulates lasting production of collagen for three months & 1.6 & 0.5 & 1.0 & 0.2 & 1.2 \\
\hline B4 & Betters skin health, e.g. acne \& wound heeling & 1.1 & 0.9 & 1.6 & 1.0 & 1.3 \\
\hline $\mathrm{C} 3$ & Use daily as healthy cosmetics & -0.1 & 1.2 & 0.8 & 0.3 & 0.9 \\
\hline D2 & See what your partner says to you & 0.5 & 1.0 & 0.3 & 1.0 & 0.7 \\
\hline $\mathrm{C} 2$ & When you're older it makes your skin younger & 0.0 & 0.8 & 1.4 & 0.9 & 1.0 \\
\hline D4 & Share with your friends so they all as good as you & 0.6 & 0.7 & 0.0 & 1.1 & 1.1 \\
\hline $\mathrm{C} 4$ & When you're young makes your skin healthy & 0.4 & 0.3 & 0.3 & 0.9 & 1.1 \\
\hline $\mathrm{C} 1$ & Even when your healthy it has beneficial effects & 0.0 & 0.7 & 0.7 & 0.7 & 0.5 \\
\hline D1 & See the results in 30 days & 0.5 & 0.8 & 0.4 & 0.7 & 0.2 \\
\hline D3 & Look at a mirror, what does it say & 0.6 & 0.9 & 0.2 & 0.5 & 0.9 \\
\hline
\end{tabular}

\section{Discussion and Conclusion}

When people think about research into cosmetics, the typical research either focuses on the performance of the products in 'objective tests', or the economics of product sales and distribution. There are occasional reports incorporating information the key mind-sets in the world of cosmetics, but the reality is that these reports do not really focus on the psychology of cosmetics, except insofar as cosmetics is considered from the point of a person's culture or daily routine. The topic of 'how to communicate' is left to the individual market research study, commissioned by a client in a company, presented, and more often than not left to molder in the stack of old, no-longer-useful reports.

Mind Genomics presents the opportunity to take topics of everyday life, like a new cosmetic, and convert a commercial report into a scientific effort. The opportunity to create science out of the everyday experience is not as recognized nor appreciated as it should be. The typical study today uses either cognitively meaningless stimuli such as non-sense syllables strung together in certain ways and presented quickly or slowly, or perhaps general stimuli in an area but none commercially meaningful. The goal is to learn about the way the mind works using the test stimuli. Perhaps an equally important goal is to learn about the performance of 'relevant' stimuli, using the mind as a measuring instrument. That is, create the science of the material studied, not the science of the mind. As demonstrated here, Mind Genomics does just that, using meaningful, 'cognitively-rich' stimuli, so both the mind doing the evaluation and the stimuli being evaluated are of interest.

\section{Acknowledgment}

Attila Gere thanks the support of the Premium Postdoctoral Researcher Program of the Hungarian Academy of Sciences.

\section{References}

1. Dimitriadis S, Papista E (2010) Integrating relationship quality \& consumer-brand identification in building brand relationships: proposition of a conceptual model. The Marketing Review 10: 385-401.

2. Liao SH, Chen YJ, Hsieh HH (2011) Mining customer knowledge for direct selling \& marketing. Expert Systems with Applications 38: 6059-6069. 
3. Papista E, Dimitriadis S (2012) Exploring consumer-brand relationship quality and identification: qualitative evidence from cosmetics brands. Qualitative Market Research: An International Journal 15: 33-56.

4. Tuncay-Zayer L, Neier S (2011) An exploration of men's brand relationships. Qualitative Market Research: An International Journal 14: 83-104.

5. Lens M (2011) Recent progresses in application of fullerenes in cosmetics. Recent Pat Biotechnol 5: 67-73. [crossref]

6. Mu L, Sprando RL (2010) Application of nanotechnology in cosmetics. Pharm Res 27: 1746-1749. [crossref]

7. Moskowitz HR, Gofman A, Beckley J, Ashman H (2006) Founding a new science: Mind genomics. Journal of sensory studies 21: 266-307.
8. Anderson NH (1981) Foundations of information integration theory. New York, Academic Press.

9. Green, PE, Srinivasan V (1990) Conjoint Analysis in Marketing: New Developments with Implications for Research and Practice. Journal of Marketing 54, 3-19.

10. Moskowitz H, Gofman A (eds.) (2012) Rule Developing Experimentation: A Systematic Approach to Understanding and Engineering the Consumer Mind. Bentham Science Publishing.

11. Gofman A, Moskowitz H (2010) Isomorphic permuted experimental designs and their application in conjoint analysis. Journal of Sensory Studies 25: 127-145.

\section{Citation:}

Konstantin Vuk Savicevic, Klodi Mengri, Attila Gere, Ryan Zemel, Petraq Papajorgji and Howard Moskowitz (2019) Understanding and Messaging A New Technology for Skin Health: A Mind Genomics Exploration. J Dermatology Stud Ther Volume 1(1): 1-11. 